\title{
EDITORIAL
}

\section{Detecting mild COPD: don't waste resources}

See linked article by Price et al. on page 15

\section{*Paul Enright ${ }^{a}$, Patrick White ${ }^{b}$}

a College of Public Health, The University of Arizona, Tucson, Arizona, USA

b Department of Primary Care and Public Health Sciences, King's College London, London, UK

*Correspondence:

Professor Paul Enright

College of Public Health,

The University of Arizona,

Tucson, Arizona

USA

E-mail: lungguy@gmail.com

Received 21/11/10
Chronic obstructive pulmonary disease (COPD) is a major and growing challenge worldwide, with evidence of under-recognition, inaccurate diagnosis, lack of emphasis on smoking cessation treatment, and inaccessibility to pulmonary rehabilitation, its most effective treatment. In this context, what are we to make of the review by Price and colleagues, previously published early online, and now in this issue of the Primary Care Respiratory Journal $(P C R J)$ ?' $^{1}$ Despite the thoroughness and laudable aims of their approach, the authors make what we consider to be an unwelcome case for earlier diagnosis and earlier treatment of this disease. It is unwelcome because medical services are already having difficulty providing optimal care for patients with clinically-important COPD. Very few countries have the capacity to expand COPD case-finding to include patients with borderline abnormal spirometry results for whom there is no evidence that treatment has any effect.

As far as we are aware, the only effective intervention in early COPD is smoking cessation. The rationale for detecting COPD early to enhance smoking cessation rates is attractive but is not supported by the evidence. There is evidence from prospective randomised studies that confronting smokers with spirometry results does not improve smoking cessation rates. ${ }^{2-5}$ Two large, uncontrolled studies from Poland showed benefits in smoking cessation associated with giving a spirometry-based diagnosis of COPD, but no effect was demonstrated in those with mild airway obstruction. ${ }^{6,7}$ A more positive note was struck by Parkes et al., who showed that informing patients of their lung age based on spirometry, followed by counselling, improved smoking cessation results irrespective of severity. ${ }^{8}$ These findings need confirmation, because an earlier similar trial and a systematic review of the impact of biomedical risk assessment as an adjunct to smoking intervention suggest otherwise. ${ }^{9,10}$ All smokers (regardless of spirometry testing) should be helped to quit, using pharmacotherapy proven to help those who are unable to quit without it. ${ }^{11}$

The concern is that we cannot predict progression of early COPD to clinically-important COPD. The majority of smokers who fall into GOLD stage I (mild COPD) do not rapidly progress to develop clinically-important COPD, even if they continue to smoke. ${ }^{12}$ Furthermore, when compared to smokers with normal spirometry results, people in GOLD stage I have the same frequency of respiratory symptoms and no decrease in exercise capacity. ${ }^{13}$

GOLD stage II ("moderate" COPD) is a broad category which includes adults with probable normal spirometry $(65-80 \%$ predicted forced expiratory volume in one second $\left[\mathrm{FEV}_{1}\right]^{14}$ ) or mild restriction (FEV $1 /$ forced vital capacity [FVC] ratio above the lower limit of the normal range but with a low FEV 1 and low FVC), with both often being associated with abdominal obesity. ${ }^{15}$ Although even a mildly low $\mathrm{FEV}_{1}$ is an independent predictor of mortality, the majority of these deaths are due to cardiovascular disease, not COPD. We consider it a disservice to these people (smokers and never-smokers alike) to be mislabelled as having moderate COPD. Somewhere below the middle of the GOLD stage II category (FEV 1 below $65 \%$ predicted), the likelihood that smokers have clinically important COPD increases substantially, with dyspnoea on exertion due to airflow limitation (which might respond to bronchodilator therapy) and a significantly increased risk of subsequent rapid loss of lung function (disease progression). Spirometry and bronchodilator responsiveness only 
Table 1. Summary of outcomes from the sub-group analyses in the TORCH and UPLIFT trials and the SPRUCE trial.

\begin{tabular}{|c|c|c|c|c|c|}
\hline & $\begin{array}{l}\mathrm{FEV}_{1} * * \\
\text { (post-BD) }\end{array}$ & $\begin{array}{l}\text { Dyspnoea } \\
\text { (SGRQ)* }\end{array}$ & Exacerbations & $\begin{array}{l}\text { Hospital } \\
\text { admission }\end{array}$ & $\mathrm{FEV}_{1}$ loss $\mathrm{ml} /$ year \\
\hline SPRUCE & $+40 \mathrm{ml}$ & No difference & $7 \%$ vs $17 \%$ & none & $\mathrm{n} / \mathrm{a}$ \\
\hline TORCH & $+100 \mathrm{ml}$ & -2.3 units & .57 vs .82 & $0.2 * * *$ & -44 vs -60 \\
\hline UPLIFT & $+100 \mathrm{ml}$ & -2.7 units & .56 vs .70 & .08 vs .10 & -43 vs -49 \\
\hline
\end{tabular}

predict $10 \%$ of the variability in the subsequent loss of lung function in continuing smokers in GOLD stage $~^{12}$ and there are currently no good biochemical markers (from blood, exhaled breath, or induced sputum) of COPD disease activity. ${ }^{16}$

Before anyone embarks on a COPD screening or case-finding programme they should be mindful to fulfil the criteria laid out by Wilson and Lunger in 1968. ${ }^{17}$ These criteria include a stipulation that there should be an accepted treatment recognised for the disease and that earlier treatment is effective. Across the whole range of COPD treatments, evidence supporting intervention with drugs in early or mild COPD (GOLD stage I) is limited, if not absent. Even with respect to short-acting bronchodilators, the evidence quoted by Price and colleagues ${ }^{1}$ from the guideline of the National Institute for Health and Clinical Excellence (NICE) in the UK, ${ }^{18}$ in the summary statement of the American Thoracic Society with the European Respiratory Society, ${ }^{19}$ and the recommendations of the Canadian Thoracic Society COPD guidelines, ${ }^{20}$ is based on interventions in patients with severe to very severe disease. Large studies of COPD inhalers have shown no differences in annual loss of lung function. ${ }^{21-23}$ Many studies of COPD inhalers show modest mean reductions in dyspnoea and small absolute reductions in exacerbation rates in patients with an $\mathrm{FEV}_{1}$ below $50 \%$ predicted. These patients were all symptomatic, all on treatment, and all recruited for these studies by pulmonary specialists. The results should not be extrapolated - as Price and colleagues have done ${ }^{1}-$ to patients with mild COPD with spirometry results above $65 \%$ predicted, who are seen predominantly by primary care providers.

Wishful thinking about COPD is reaching epidemic proportions, and despite their best intentions the review by Price and colleagues ${ }^{1}$ is an example. The authors cite three trials which they say demonstrate the advantages of maintenance therapy (prescription of daily inhalers) in early COPD. ${ }^{24-26}$ The first two are subgroup analyses from the TORCH and UPLIFT trials, and the third is their own SPRUCE trial. The majority of participants in the GOLD stage II components of the TORCH and UPLIFT trials had a baseline $\mathrm{FEV}_{1}$ in the lower half of GOLD stage II, and in the case of SPRUCE, most participants were in GOLD stage III. The TORCH and UPLIFT studies each included more than 2000 patients with COPD from pulmonary specialist offices worldwide and followed them for three or four years. The SPRUCE study, performed in 44 primary care practices in the UK, was small and short ( $n=178$ followed for three months). COPD outcomes measured in these studies included short-term changes in FEV 1 , quality of life dyspnoea scores, exacerbation rates, hospital admission rates, and annual rate of $\mathrm{FEV}_{1}$ decline (see Table 1).

From the patients' standpoint there was little to offer in these studies in terms of improvement in dyspnoea, the major manifestation of disease in COPD. GOLD stage II participants in the active treatment arms of the TORCH and UPLIFT studies reported statistically significant better quality of life (St George's Respiratory Questionnaire - SGRQ) than those using placebo inhalers, but the improvement was well below the minimum clinically important difference for the SGRQ (-4.0 units). ${ }^{27}$ The SPRUCE study showed no improvement in dyspnoea for patients randomised to take tiotropium for three months. The mean $\mathrm{FEV}_{1}$ increases in these studies $(+40$ to $+100 \mathrm{ml}$ ) were in the range of the mean $77 \mathrm{ml}$ increases seen after salbutamol in a large population-based sample of relatively healthy adults. ${ }^{28}$ We see no reason to encourage patients to take a long-acting bronchodilator if their dyspnoea is not relieved soon after taking the drug. The rate of decline in postbronchodilator $\mathrm{FEV}_{1}$ in the TORCH study was $16 \mathrm{ml}$ per year better in the combination inhaled long-acting $\beta$-agonist and corticosteroid intervention group. In UPLIFT, the rate of decline in postbronchodilator $\mathrm{FEV}_{1}$ was $6 \mathrm{ml}$ per year better in the tiotropium group compared to the placebo group, an annual advantage of $0.3 \%$ in the rate of decline in lung function. After ten years of faithfully taking an inhaler every day, these patients would only have $3-4 \%$ better lung function (on average).

Finally, since there is no evidence of benefit for the use of inhaled corticosteroids in the mild or moderate stages of COPD, it is surprising that Price and colleagues mention these drugs in this context.

Interest in the early detection and treatment of COPD may have arisen from the awareness of the growing challenge of COPD worldwide. However, we believe this optimism to be misplaced because there is no evidence that inhalers in early COPD have benefits which outweigh the costs and risks. Promoting interest in early COPD risks the diversion of limited health resources away from interventions such as smoking cessation treatment, which is highly effective. ${ }^{29}$

\section{References}

1. Price D, Freeman D, Cleland J, Kaplan A, Cerasoli F. Earlier diagnosis and earlier treatment of COPD in primary care. Prim Care Respir J 2011;20(1):15-22. http://dx.doi.org/10.4104/pcrj.2010.00060

2. Buffels J, Degryse J, Decramer M, Heyrman J. Spirometry and smoking cessation advice in general practice: a randomised clinical trial. Respir Med 2006;100(11):2012-17. http://dx.doi.org/10.1016/j.rmed.2006.02.014 
3. Wilt TJ, Niewoehner D, Kane RL, MacDonald R, Joseph AM. Spirometry as a motivational tool to improve smoking cessation rates: a systematic review of the literature. Nicotine Tob Res 2007;9(1):21-32. http://dx.doi.org/ 10.1080/14622200601078509

4. Lin KW. Screening for chronic obstructive pulmonary disease using spirometry. Am Fam Physician 2009;80(8):861.

5. Kotz D, Wesseling G, Huibers MJ, van Schayck OC. Efficacy of confronting smokers with airflow limitation for smoking cessation. Eur Respir J 2009;33 (4):754-62. http://dx.doi.org/10.1183/09031936.00116308

6. Górecka D, Bednarek M, Nowifski A, PuÊcifska E, Goljan-Geremek A, Zielifski J. Diagnosis of airflow limitation combined with smoking cessation advice increases stop-smoking rate. Chest 2003;123(6):1916-23. http://dx.doi.org/ 10.1378/chest.123.6.1916

7. Bednarek M, Gorecka D, Wielgomas J, et al. Smokers with airway obstruction are more likely to quit smoking. Thorax 2006;61(10):869-73. http://dx.doi.org/10.1136/thx.2006.059071

8. Parkes G, Greenhalgh T, Griffin M, Dent R. Effect on smoking quit rate telling patients their lung age: the Step2quit randomized controlled trial. BMJ 2008; 336:598-600.

9. Lipkus IM, Prokhorov AV. The effects of providing lung age and respiratory symptoms feedback on community college smokers' perceived smoking-related health risks, worries and desire to quit. Addictive Behav 2007;32:516-32. http://dx.doi.org/10.1016/j.addbeh.2006.05.018

10. Bize R, Burnand B, Mueller $Y$, Cornuz J. Biomedical risk assessment as an aid for smoking cessation. Cochrane Database Syst Rev 2005;(4):CD004705.

11. vanSchayck OC, Pinnock $H$, Ostrem A, et al. IPCRG Consensus statement: tackling the smoking epidemic - practical guidance for primary care. Prim Care Respir J 2008;17(3):185-93. http://dx.doi.org/10.3132/pcrj.2008.00060

12. Scanlon PD, Connett JE, Waller LA, Altose MD, Bailey WC, Buist AS. Smoking cessation and lung function in mild-to-moderate chronic obstructive pulmonary disease. The Lung Health Study. Am J Respir Crit Care Med 2000;161(2 Pt 1):381-90.

13. Pinto-Plata VM, Celli-Cruz RA, Vassaux C, et al. Differences in cardiopulmonary exercise test results by American Thoracic Society/European Respiratory SocietyGlobal Initiative for Chronic Obstructive Lung Disease stage categories and gender. Chest 2007;132(4):1204-11. http://dx.doi.org/10.1378/chest.07-0593

14. Miller MR, Quanjer PH, Swanney MP, Ruppel G, Enright PL. Interpreting lung function data using 80 percent of predicted and fixed thresholds misclassifies over 20\% of patients. Chest 2010;Jun 3. [Epub ahead of print]

15. Leone N, Courbon D, Thomas F, et al. Lung function impairment and metabolic syndrome: the critical role of abdominal obesity. Am J Respir Crit Care Med 2009;179(6):509-16. http://dx.doi.org/10.1164/rccm.200807-11950C

16. Vestbo J, Rennard S. Chronic obstructive pulmonary disease biomarker(s) for disease activity needed--urgently. Am J Respir Crit Care Med 2010;182(7):863-4.
http://dx.doi.org/10.1164/rccm.201004-0602ED

17. Wilson JMG and Jungner G. Principles and Practice of Screening for Disease, WHO 1968

18. O'Reilly J, Jones MM, Parnham J, Lovibond K, Rudolf M; Guideline Development Group. Management of stable chronic obstructive pulmonary disease in primary and secondary care: summary of updated NICE guidance. BMJ 2010;340:C3134.

19. Celli BR, MacNee W; ATS/ERS Task Force. Standards for the diagnosis and treatment of patients with COPD: a summary of the ATS/ERS position paper. Eur Respir J 2004;23(6):932-46. http://dx.doi.org/10.1183/09031936.04.00014304

20. O'Donnell DE, Hernandez P, Kaplan A, et al. Canadian Thoracic Society recommendations for management of chronic obstructive pulmonary disease 2008 update - highlights for primary care. Can Respir J 2008;15Suppl A:1A-8A.

21. Anthonisen NR. Lessons from the Lung Health Study. Proc Am Thorac Soc 2004; 1(2):143-5. http://dx.doi.org/10.1513/pats.2306033

22. Celli BR, Thomas NE, Anderson JA, et al. Effect of pharmacotherapy on rate of decline of lung function in chronic obstructive pulmonary disease: results from the TORCH study. Am J Respir Crit Care Med 2008;178(4):332-8. http://dx.doi.org/10.1164/rccm.200712-18690C

23. Tashkin DP, Celli B, Senn S, et al. UPLIFT Study Investigators. A 4-year trial of tiotropium in chronic obstructive pulmonary disease. N Engl J Med 2008; 359(15):1543-54. http://dx.doi.org/10.1056/NEJMoa0805800

24. Jenkins CR, Jones PW, Calverley PM, et al. Efficacy of salmeterol/fluticasone propionate by GOLD stage of chronic obstructive pulmonary disease: analysis from the randomised, placebo-controlled TORCH study. Respir Res 2009; 10:59-68.

25. Decramer M, Celli B, Kesten S, Lystig T, Mehra S, Tashkin DP; UPLIFT investigators. Effect of tiotropium on outcomes in patients with moderate chronic obstructive pulmonary disease (UPLIFT): a prespecified subgroup analysis of a randomised controlled trial. Lancet 2009;374(9696):1171-8. http://dx.doi.org/10.1016/S0140-6736(09)61298-8

26. Freeman D, Lee A, Price D. Efficacy and safety of tiotropium in COPD patients in primary care--the SPiRiva Usual CarE (SPRUCE) study. Respir Res 2007;8:4555. http://dx.doi.org/10.1186/1465-9921-8-45

27. Jones PW. St. George's Respiratory Questionnaire: MCID. J of Chronic Obstructive Pulmonary Disease 2005;2:75-9. http://dx.doi.org/10.1081/COPD200050513

28. Kainu A, Lindqvist A, Sarna S, Lundbäck B, Sovijärvi A. FEV1 response to bronchodilation in an adult urban population. Chest 2008;134(2):387-93. http://dx.doi.org/10.1378/chest.07-2207

29. Anthonisen NR, Skeans MA, Wise RA, Manfreda J, Kanner RE, Connett JE; Lung Health Study Research Group. The effects of a smoking cessation intervention on 14.5-year mortality: a randomized clinical trial. Ann Intern Med 2005; 142(4):233-9.

\section{Available online at http://www.thepcrj.org}

